\title{
Effectiveness of aerobic exercise and strengthening on the cardiorespiratory endurance of Paralympic basketball players
}

\author{
Teddy Bofosa ${ }^{1}$, (iD) Betty Miagindula ${ }^{1}$, \\ (i) Constant Nkiama ${ }^{1}$ \\ ${ }^{1}$ Department of Physical Medicine and Rehabilitation, Kinesiology Service, University Clinics of Kinshasa, Faculty of Medicine, University \\ of Kinshasa, Democratic Republic of Congo.
}

\begin{abstract}
The aim of this study was to evaluate the effects of aerobic exercise and strengthening on the cardiorespiratory endurance of Paralympic basketball players. The present study was carried out within Kinshasa Martyrs Stadium in the club of Congolese association of sports for handicapped and disabled) and in three towns of Kinshasa. A total of 75 disabled persons were randomly divided into two groups: the first group (experimental) was composed of 35 Paralympic basketball players' (beginners) with a mean age of $32.03 \pm 9.06$ years and a sitting height of $43.86 \pm$ $6.75 \mathrm{~cm}$ (were subjected to a three-wheel-strength wheelchair basketball and weight training program sessions of two hours a week) and the second (control) of 40 disabled persons who live in three towns of Kinshasa with a mean age of $33.2 \pm 2.75$ years and a sitting height of $44.07 \pm 3.5 \mathrm{~cm}$.The paired student parametric test $t$ allowed us to verify the effects of physical activity on weight, waist circumference, systolic blood pressure, blood pressure diastolic, resting heart rate, forced expiratory volume and the maximum oxygen uptake after 6 months. The Paralympic basketball players' have reduced significantly their weight, waist circumference, systolic blood pressure, blood pressure diastolic, resting heart rate, respiratory rate and blood glucose than control group $(\mathrm{p}<.05)$. In addition they increased significantly their forced expiratory volume and maximum oxygen uptake than control group $(p<.05)$. The regular practice of adapted physical activities allows people
\end{abstract}

with physical disabilities to improve their physiological profile.

Keywords. Aerobic exercise, muscle building, Paralympic basketball players.

\section{Introduction}

It is estimated that more than one billion people live with some form of disability, about $15 \%$ of the world's population (based on population estimates for 2010). This figure is higher than the World Health Organization's previous estimate, which dates back to the 1970s and referred to a proportion of around 10\% (Ravaud \& Mormiche, 2003).

In the Democratic Republic of Congo, demographic indicators indicate that since 1984, there has never been a census of the total population living in the DRC, only estimates have been used in recent years, the latest estimate of the Government date of the year 2011, and reported more or less 70,000,000 inhabitants. As far as disabled people are concerned, the statistics are poorly developed, so far only the poorly documented surveys generally carried out by the Organization of National and International Persons with Disabilities in a part of the country

Received: March 19, 2019 - Accepted: April 15, 2019 - Published: June 20, 2019

To cite this article: Bofosa T, Miagindula B, Nkiama C. Effectiveness of aerobic exercise and strengthening on the cardiorespiratory endurance of paralympic basketball players. Turk J Kinesiol, 2019; 5(2): 57-62.

凶T. Bofosa, e-mail: bofosa.linkoko@unikin.ac.cdＤOI: 10.31459/turkjkin.529212 
have been used for the most recent years by persons with disabilities is estimated at 10,500,000 disabled people, which makes up in percentage terms almost $15 \%$ of the population (Bouvier \& Niel, 2010).

Physical inactivity (lack of physical activity) is considered to be the fourth leading risk factor for death worldwide $(6 \%)$. It is also estimated to be the main cause of $21-25 \%$ of breast and colon cancers, $27 \%$ of diabetes cases and approximately $30 \%$ of cases of ischemic heart disease (Bouvier, 2009; Amar \& Amira, 2003).

Sports practice leads to changes in lifestyle and by reducing the risk factors associated with sedentary lifestyle, and are presented as beneficial to health. A recent report by the US Department of Health concludes that, regardless of age and gender, regular and moderate physical activity is beneficial to health and that benefit increases with duration and / or time, intensity of this practice (White, 2009).

Sports are encouraged by many campaigns promoting sport as a factor of good health, promoting the physical and moral development of the individual.

It is always possible to find a physical activity compatible with a motor handicap. For the physical handicaps, the contraindications are rare and are most often temporary, as they can be in the valid ones (Varray et al., 2001).

Admittedly, there are a number of specificities related to the specificity of most disabilities (Bouvier G, 2009). One of the main concerns for people with physical disabilities wishing to practice a sport is to integrate or reintegrate into the world of the valid ones, either in a playful setting or in a competitive environment. Some sports particularly favor this insertion, such as basketball, archery or weapons, tennis ... (Breton, 1995). It is worth remembering that the National Paralympic Committee of the Democratic Republic of Congo is officially part of the International Paralympic Committee.

Performance is currently evolving. They progress faster than in the valid ones. This progression is linked to the recent appearance of competitions for the physically handicapped and to the improvement of the sports equipment used (Snowling \& Hopkins, 2006; Martin Ginis et al., 2003). Wheelchairs are becoming lighter and prostheses are better adapted for amputees.

The issue of the sedentary lifestyle of these people is underlined by the development of the cyclical process of the hypodynamic / hypokinetic syndrome put in place by C. Simard: the sedentary lifestyle and its effects lead to a sedentary life as a constant way of life. The concept of physical activity is therefore clearly at the interface between medical and educational (Jacobi al., 2010). It helps to fight against this phenomenon at best by increasing the rhythm of life of these by opening up new horizons, keeping them healthier and improving their overall quality of life (Baron et Caouette, 1999).

The body of literature in this field often demonstrates the specificity of APA interventions in this population, the importance of developing research in this area and setting up targeted intervention programs ... (Brunet, 1999).

However, we found that in Kinshasa people with disabilities practice adaptive, healthenhancing physical activities, but no study refers to assessments of its effects before and after practice, which is why we are conducting this study.

\section{Methods}

This evaluative study was conducted from December 2017 to June 2018 in the club of the Congolese association of sports for handicapped and disabled (coaching structure disabled athletes) stage of the martyrs of Kinshasa. It consisted in evaluating the physiological profile of 35 disabled athletes (beginner) before and after the practice of adapted physical activities compared to a control group made up of 40 disabled people living in three communes of Kinshasa.

All Paralympic basketball players' subjects had consented to participate in the study according to the Helsinki Declarations. The information collected from Paralympic basketball players' was kept confidential. 
Included in this study were black athletes of the Bantu ethnic group, at least 18 years of age, exempt from all pathologies that might contraindicate the practice of physical activity (severe hypertension, uncontrolled diabetes, severe anemia). etc.), with a disability free of all complications. Athletes were also required to be exempt from tobacco or alcohol consumption during physical activity and also to consent to participation in the study.

The subjects did not benefit at any time from a particular dietary instruction. Of 100 athletes approached, 10 were excluded for various reasons.

Of the total reduced to 90 athletes, there were 15 additional exclusions during study for voluntary discontinuation $(\mathrm{n}=6)$, health problem $(\mathrm{n}=4)$, lack of time $(\mathrm{n}=3) ; 2$ athletes were lost sight of. The final experiment thus covered 75 subjects.

\section{Measurements and Data Collection}

All anthropometric and physiological measurements for both groups (experimental and control) were taken once before the first exercise session and a second time after the last session. The sitting height of the subjects was measured using a Seca measuring system (model 220), to the nearest centimeter. The subjects were weighed on a Seca balance (alpha 770 model), to 100 grams. Waist circumference was measured using a metric tape. The blood pressure $(\mathrm{mmHg})$ was measured with a wrist blood pressure monitor, which at the same time allows us to determine the resting heart rate.

The volume of air exhaled in one second during forced expiration after maximal inspiration (FEV1) was evaluated using a PIKO-6 brand spirometer. Glycaemia was measured by the biologist physician on an empty stomach using a one touch glucose meter.

Cooper's 12-minute test was used to assess the cardiorespiratory endurance level of athletes with disabilities; he would have to travel the furthest distance with his wheelchair in 12 minutes.

All these measures were taken once before the intervention program and after the program by kinesiologist team.

\section{Description of the Program for Experimental Group}

Wheelchair basketball and weight training was practiced on a regular basis and consisted of passing, dribbling and shooting exercises. The session was divided into three warm-up periods, the body of the session and the return to calm. The subjects should hydrate within 15 to 30 minutes before the session and during the session. Heart rate monitors (Polar Electro; Oy, Kempele, Finland) were used to adjust workloads to achieve target heart rate. The total duration of a session was two hours a day due to three sessions per week of moderate to severe intensity.

\section{Data Analysis}

The data was entered using the Microsoft Excel 2013 software and then imported into SPSS software version 21.0 (Statiscal Package for Social Sciences) for appropriate analysis. In univariate analysis, the paired Student t-test was used to compare the means between the intervention and control group. The data are represented as mean \pm standard deviation in the tables. The statistical test results used are interpreted at the significance level $\mathrm{p}<0.05$ for statistical decision making.

\section{Results}

There was no significant difference between the Paralympic group and the control group before the intervention program (Table 1).

Table 2 shows that Paralympic athletes significantly improved their weight, waist circumference, systolic blood pressure, heart rate, respiratory rate, forced expiratory volume, maximal oxygen uptake and blood glucose more than sedentary people with disabilities $(\mathrm{p}<0.05)$. 
Table 1

Comparison of the average values of the two groups before the intervention program (Mean $\pm \mathrm{SD}$ ).

\begin{tabular}{lccc}
\hline Parameters & Experimental Group & Control Group & $\mathrm{p}$ \\
\hline Age (years) & $32.03 \pm 9.06$ & $33.2 \pm 2.7$ & 1.42 \\
Seating height (cm) & $43.86 \pm 6.95$ & $44.01 \pm 3.5$ & 1.26 \\
Weight (kg) & $82.01 \pm 2.25$ & $81.83 \pm 1.67$ & 0.063 \\
Waist circumference (cm) & $80.43 \pm 6.65$ & $87.02 \pm 4.42$ & 0.071 \\
Systolic blood pressure (mmHg) & $130.35 \pm 10.06$ & $131.68 \pm 12.2$ & 0.239 \\
Diastolic blood Pressure (mmHg) & $83.51 \pm 9.23$ & $83.03 \pm 8.47$ & 0.492 \\
Heart rate (beat per min) & $86.46 \pm 5.02$ & $85.9 \pm 4.93$ & 0.065 \\
Respiratory rate (Cycle/min) & $18.73 \pm 1.67$ & $20.26 \pm 0.25$ & 0.0861 \\
FEV(\%) & $73.06 \pm 3.81$ & $72.03 \pm 6.41$ & 0.074 \\
VO²max (ml.min-1.kg-1) & $59.44 \pm 12.28$ & $60.29 \pm 9.74$ & 0.096 \\
Blood glucose (mg/dl) & $119.63 \pm 7.02$ & $118.56 \pm 10.3$ & 0.082 \\
\hline
\end{tabular}

Table 2

Comparison of the average values of the two groups after the intervention program (Mean $\pm \mathrm{SD}$ ).

\begin{tabular}{lccc}
\hline Parameters & Experimental Group & Control Group & $\mathrm{p}$ \\
\hline Weight $(\mathrm{kg})$ & $77.21 \pm 1.03$ & $81.83 \pm 1.67$ & $0.002^{*}$ \\
Waist circumference $(\mathrm{cm})$ & $76.04 \pm 2.33$ & $86.18 \pm 10.51$ & $0.01^{*}$ \\
Systolic blood pressure (mmHg) & $125.63 \pm 7.96$ & $129.74 \pm 17.06$ & $0.042^{*}$ \\
Diastolic blood Pressure (mmHg) & $80.05 \pm 6.11$ & $83.03 \pm 8.47$ & $0.002^{*}$ \\
Heart rate (beat per min) & $80.12 \pm 7.43$ & $84.22 \pm 7.93$ & $0.005^{*}$ \\
Respiratory rate (Cycle/min) & $14.45 \pm 0.18$ & $20.26 \pm 0.25$ & $0.003^{*}$ \\
FEV(\%) & $77.68 \pm 6.09$ & $70.64 \pm 1.55$ & $0.03^{*}$ \\
VO²max (ml.min-1.kg-1) & $64.33 \pm 8.92$ & $58.16 \pm 11.07$ & $0.001^{*}$ \\
Blood glucose (mg/dl) & $114.02 \pm 5.02$ & $120.81 \pm 8.04$ & $0.002^{*}$ \\
\hline${ }^{*}$ p $<.05$ & & &
\end{tabular}

\section{Discussion}

The present study aimed to verify the impact of regular physical activity adapted wheelchair basketball and bodybuilding on the physiological parameters of athletes with physical disabilities.

Bofosa et al. (2018) have shown that regular physical activity can reduce weight and waist circumference. These results corroborate those found in our study which showed that the group exercising significantly reduced their weight and waist compared to the control group.
A MEDLINE-type research conducted by Grassi et al. (1992) using the arsenal anti hypertension (HTA) key words and exercises, teaches us that more than 1,500 articles were written on the subject over the past 20 years (Grassi et al., 1992; Balducci et al., 2006; Gordon et al., 2009). All of these articles confirm that regular exercise reduces blood pressure (BP) values by an average of 10/7.1.Or, we know that such an improvement in BP allows to expect a reduction incidence of stroke and myocardial infarction by $34 \%$ and $19 \%$ respectively, which is comparable to the effect of any antihypertensive drug used as 
monotherapy (Ryan et al., 2001; Baum et al., 2007). In our study, the decrease in blood pressure was significantly reduced in favor of subjects in the experimental group. Physical fitness has been shown to be the ability to perform physical activity by bringing into play a full range of physiological and psychological resources. It is measured by putting into play the bodily functions (musculoskeletal). Fitness is considered an indicator of an individual's health (Skowronski, 2009). Muscular endurance is essential for the performance of daily life and leisure activities, as well as for the ability to work. Lower muscle endurance may limit the physical activity of physically disabled people. In our study, the experimental group subjects significantly improved their resting heart rate, respiratory rate, maximal oxygen consumption compared with the control group. This could be justified by the fact that the physical condition improves when it is sufficiently stimulated. In this sense, the WHO recommends the practice of a physical activity of at least $30 \mathrm{~min} /$ day for the adult or $60 \mathrm{~min} /$ day for the children (WHO, 2010). These recommendations do not exist for people with physical disabilities, but in terms of public health it is obvious that it is necessary to provide regular and sufficient physical activity to these people. The subjects of our control group not practicing the physical exercises their physical condition deteriorates.

\section{Conclusion}

The objective of this study was to evaluate the impact of the regular practice of adapted physical activities on the physiological characteristics of athletes with disabilities of the Congolese Disabled and Disabled Sports Association of Kinshasa.

This study shows that the regular practice of adapted wheelchair basketball type physical activity combined with bodybuilding exercises allows physically disabled athletes to significantly improve their physiological parameters, in particular their cardiorespiratory adaptation to exercise.
The rehabilitation professional must use physical exercise as a tool for the care of their patients with reduced mobility in the same way as the other therapeutic means used.

\section{Conflicts of Interest}

The authors declare that they have no conflict of interest in this article.

\section{Acknowledgement}

Our thanks to the authorities of the National Committee of the Democratic Republic of Congo for the provision of this research and the Paralympic basketball players to have agreed to work with us.

\section{References}

Amar M, Amira S. Disabilities, administrative recognition of disability and access to employment: the contributions of HID. French Review of Social Affairs, 2003: 1-2: 149-165.

Balducci S, Iacobellis G, Parisi L, Di Biase N, Calandriello E, Leonetti F, Fallucca F. Exercise training can modify the natural history of diabetic peripheral neuropathy. Journal of Diabetes Complications, 2006; 20: 216-223

Baron M, Caouette M. Programme d'intervention en APA auprès de personnes handicapée à mobilité réduite : lutte contre la sarcopénie, Hôpital Rivière des prairies Montréal Québec, (inédit), 1999.

Baum K, Votteler T, Schiab J. Efficiency of vibration exercise for glycemic control in type 2 diabetes patients. Internal Journal of Medicine Science, 2007; 4: 159-163.

Bofosa T, Kam E, Miagindula B, Muela D, Nkiama C, Njimbu F. Cardiorespiratory health and body composition of type 2 diabetics' patients: Effect of a program of adapted physical activity. Turk J Kinesiol, 2018; 4(4): 118-124.

Boulé, NG, Haddad E, Kenny, GP, Wells GA, Sigal RJ. Effects of exercise on glycemic control and body mass in type 2 diabetes mellitus: a meta-analysis of controlled clinical trials. JAMA, 2001; 286: 1218-27.

Bouvier G. The disability approach by functional limitations and activity restriction among adults aged 20 to 59, France portrait social 2009, INSEE, pp. 125-142.

Bouvier G, Niel X. Discrimination related to disability and health. INSEE first, No. 1308, 2010.

Breton D. The social mirror of disability. In Journal des Psychologues, 1995; (130): 26-28.

Brunet F. Physical activities adapted to people with major disabilities: from the biomedical model to the 
psychosocial and cultural model, in Brunet (F) Bui-Xuan (G) Mental disability mental disorders and sport, FFSA / AFRAPS , Cl-Ferrand. 1999, pp. 402-455.

Cornelissen VA, Buys R, Smart NA. Endurance exercise beneficially affects ambulatory blood pressure: a systematic review and meta-analysis. Journal of Hypertension, 2013; 31: 639-48.

Gordon BA, Benson AC, Bird SR, Fraser SF. Resistance training improves metabolic health in type 2 diabetes: A systematic review. Diabetes Research Clinic Practice, 2009; 83: 157-175.

Grassi G, Servalle G, Calhoun D, Bolla GB, Mancia G. Physical exercise in essential hypertension. Chest, 1992; 101: 312.

Jacobi D, Ciangura C, Couet C, Oppert JM. Physical activity and weight loss following bariatric surgery. Obese, 2010; 4(3): 230-240.

Ginis KAM, Latimer AE, McKechnie K, Ditor DS, McCartney N, Hicks AL, Bugaresti J, Craven BC. Using exercise to enhance subjective well-being among people with spinal cord injury: The mediating influences of stress and pain. Rehabilitation Psychology, 2003; 48(3): 157-164.

Miller G, Brunet F, Dejean P. Physical activity, health, quality of life: survey of physical activity, health and quality of life for people with intellectual disabilities, CAT in handicap. Social Sciences and Humanities Review, 2000; 85(7): 102-110.

Millet G, Perrey S. Ellipses, Physiologie du sport. Bases physiologiques des activités physiques et sportives, 4e édition, Masson, Paris 2005.
Olivier B, Patricia S. Activités physiques adaptées aux personnes vivant avec des capacités très réduites, Actes du colloque européen de Bordeaux 28 au 29 septembre 2000, Paris, FFSA 2001.

Ravaud JF, Mormiche P. Health and disabilities, causes and consequences of social Inequalities. Understanding Inequalities, 2003, no. 87-106.

Ryan AS, Hurlbut DE, Lott ME, Ivey FM, Fleg J, Hurley BF, Goldberg AP. Insulin action after resistive training in insulin resistant older men and women. Journal of American Geriatric, 2001; 49: 247-253.

Simard C. Impact of sedentarism and physical activity on mental functions Integration with the International Classification of Disabilities and Handicaps (ICIDH), in Brunet F, Caouette $\mathrm{M}$ under the direction, Corps and Psychiatry Psychopedagogy of Physical and Sports Activities Rennes, In ENSP Edition, 1995 p.130-137

Skowronski W, Horva M, Nocera J, Roswal G, Scroce R. Eurofit special: European fitness battery score variation among individuals with intellectual disability. Adapt Phys Activ Q, 2009; 126: 54-67.

Snowling, NJ, Hopkins WG. Effects of different modes of exercise training on glucose control and risk factors for complications in type 2 diabetic patients. Diabetes Care, 2006; 29: 2518-27.

Varray A, Bilard J, Ninot G. Teach and animate adapted physical activities. EPS file, 55. Paris: EPS 2001.

White A. The professional integration of disabled workers, Edition PUG, Collection Handicap aging society, 2009.

WHO. Global Recommendations on Physical Activity for Health. Geneva, Switzerland, 2010; pp. 1-58. 